\title{
Presentación
}

\section{Desafíos para las memorias de hoy. Reconocimiento del dolor y la resiliencia de la otredad}

Los resultados electorales y los debates políticos en Europa, Latinoamérica y los Estados Unidos en los últimos años, muestran lo que algunos académicos y líderes de opinión denominan como un giro hacia la derecha, es decir, una tendencia hacia políticas, saberes y prácticas que apuntan a la restricción de derechos y libertades; a los desconocimientos y exclusiones culturales, artísticos y científicos; a la profundización del capitalismo y el desarrollismo económico, y a ejercicios de poder autoritarios ${ }^{1}$.

Las memorias de los efectos producidos por este tipo de tendencias en el pasado, como lo sucedido en la Alemania nazi, o los bombardeos de Hiroshima y Nagasaki, o las experiencias de las dictaduras en Sur América, se han convertido en referentes que buscan movilizar en el presente las razones y emociones de votantes, ciudadanos y seres interesados en la democracia, la equidad, la justicia y la misma sobrevivencia del planeta para hoy y el futuro. En Colombia, por ejemplo, el debate y las movilizaciones políticas generadas por la designación del director del Centro Nacional de Memoria Histórica, han puesto en el ojo del huracán el valor de las historias en un Estado-nación que aún no supera el conflicto armado y se debate en la esquizofrenia de reconocer o no su existencia.

Todo esto está sucediendo en medio de lo que Huyssen (2002) denomina un boom de la memoria en el mundo occidental, en el que el pasado y las historias han adquirido un rol central en la vida contemporánea, evidenciando las dificultades y también

1. Ver por ejemplo: Aisch, Gregor; Pearce, Adam; Rousseau, Bryant (23 de octubre de 2017). How Far Is Europe Swinging to the Right? The New York Times. Recuperado de https:/www.nytimes.com/interactive/2016/05/22/world/europe/europe-right-wing-austria-hungary.html; Angela Merkel says Europe needs to "stand up" against far right as Austrian government falls (18 de mayo de 2019). ABC. Recuperado de https://www.abc.net.au/news/2019-05-19/angela-merkel-calls-for-defence-against-far-right/11127618; Gamboa, Santiago (23 de febrero de 2019). La “derechización” criolla. ElEspectador. Recuperado de https:// www.elespectador.com/opinion/la-derechizacion-criolla-columna-841282 
decepciones sociales por no alcanzar fines como la libertad, la solidaridad y la vida en paz, entre otras promesas hechas por la modernidad. El boom de las memorias y del pasado nos enfrenta, además, con la explosión de múltiples violencias políticas y culturales, así como de conflictos armados internos, como el colombiano, que no pocos políticos, líderes de opinión y ciudadanos, conciben o como una guerra civil, o como el fracaso total o parcial del Estado, e incluso como una amenaza terrorista, atizando el fuego y las pasiones en una sociedad altamente polarizada.

En medio de estos fenómenos políticos, históricos y científicos se produce este muy oportuno número sobre memorias plurales que busca sumar a los esfuerzos de pedagogía, comunicación e investigación sobre las historias en América Latina; a los esfuerzos de movimientos y organizaciones sociales, académicos e instituciones estatales para recuperar y conservas las memorias, y al histórico trabajo encargado a la Comisión de la Verdad de Colombia, en un tiempo en que las versiones y disputas sobre el pasado cobran mayor importancia para el presente y futuro de nuestros países.

Para este número que inició como una iniciativa conjunta con la Revista Colombiana de Antropología, del Instituto Colombiano de Antropología e Historia (Icanh), recibimos más de 30 artículos y reseñas de textos, varios de ellos de países de América Latina y España. De estos, 16 artículos continuaron en proceso de evaluación, de los cuales 8 fueron encaminados hacia la $R C A$ y otros 8 a la Revista CS. De los 8 que continuaron su camino con nosotros, presentamos 5 que hacen parte del primer grupo de textos de este número. Sin proponérnoslo, todos ellos están relacionados con innovadores acercamientos a diferentes dimensiones del conflicto armado en Colombia, e incluyen juiciosos análisis sectoriales, territoriales y locales. Además, 3 de los artículos abordan temas de interés para la región Pacífica (Río Pance, Trujillo y Norte del Cauca), donde tiene sus vínculos más fuertes la Revista CS.

El primer artículo, "En medio de la violencia: recursos, tácticas y violencia contra el sector ganadero" (Ponce de León, 2019), hace una rigurosa descripción y análisis de una robusta base informativa constituida por una encuesta realizada a 4129 ganaderos que declararon ser víctimas del conflicto armado en Colombia, y documenta cerca de 7000 hechos de violencia en las principales regiones de producción ganadera del país entre 1950 y 2012. El trabajo adoptó un enfoque etnográfico que apuesta por interpretar los modos de vida en que cobran sentido las prácticas de los ganaderos. El texto permite ver las formas como empresarios de este sector reaccionaron a diferentes prácticas y actores del conflicto: cooperar, negociar, postergar o negarse ante las presiones y demandas de los armados e ilegales. El artículo ofrece evidencias para comprender mejor la complejidad que hay en los vínculos entre sectores de la población civil y los grupos armados, mostrando que las reacciones de los ganaderos, antes que obedecer a decisiones políticas, revelan muchas veces sus 
preocupaciones por la propia vida y la de sus familias. Con testimonios, el artículo muestra que sobrevivir a una guerra requería soluciones "prácticas": las preguntas éticas y la política vendrían después.

El segundo texto, "Paseo, sancocho y río. Memorias y olvidos sobre el conflicto armado en Pance, Cali", de Medina-Vargas, Bolaños-Martínez y Barón (2019), recoge trabajos de investigación de corte etnográfico realizados en el corregimiento de Pance, Cali, para observar las relaciones de las memorias del conflicto armado con la vida cotidiana, las identidades y los olvidos, y sus relaciones con el mundo natural de la zona y sus tradiciones locales. El trabajo recoge las remembranzas de pobladores que han dedicado sus vidas al negocio del sancocho de gallina a las orillas del río Pance. Sus relatos ayudan a dar visibilidad y a analizar sus vivencias y recuerdos en momentos en los que se escaló el conflicto armado en el país y la región, mostrando cómo sus memorias, pero también sus olvidos, buscan proteger a la comunidad, los ecosistemas y el tradicional paseo de los domingos, principales fuentes de vida presentes y futuras en este territorio. El texto permite evidenciar articulaciones de las memorias, las identidades y los olvidos, y sus relaciones con los ríos, los bosques y la fauna de la zona, así como con diferentes tradiciones locales como el paseo de olla. De esta forma, los autores proponen una discusión que se interroga sobre la banalización de las violencias del conflicto armado y la existencia de hegemonías de las memorias que excluyen los recuerdos de violencias cotidianas producidas en territorios particulares.

El tercer texto, "Valoración patrimonial del Parque-Monumento, Trujillo, Colombia: memorial democrático al servicio de una comunidad de memoria" (Garzón-Ochoa, 2019), retrata las tensiones y disputas entre diversos agentes sociales alrededor de los monumentos y los lugares de memoria, como los denomina Nora (2008). El texto describe y analiza el trabajo y materialización de una comunidad de memoria que logra construir un lugar de diálogo que identifica el sentir de las víctimas en el Parque-Monumento de Trujillo, Valle del Cauca, donde según el Grupo de Memoria Histórica se registraron más de 340 víctimas de homicidios, torturas y desapariciones forzadas entre 1988 y 1994. El autor muestra cómo en este lugar no solo emergen valores positivos, sino también antivalores o valores negativos, que evidencian la existencia de contramemorias y la vitalidad misma del pasado.

El cuarto texto, "Narrativas comunitarias y dinámicas territoriales del proceso de implementación del Acuerdo de Paz en Miranda, Cauca (2016-2018)" (Vélez-Torres, 2019), es producto de un trabajo etnográfico que resultó del acompañamiento al proceso de implementación de varios de los compromisos firmados entre la guerrilla y el gobierno. El texto logra mostrar los enfrentamientos entre memorias centrales (las del Estado y otras instituciones) y 
memorias periféricas, dejando ver las pugnas por la hegemonía de la memoria -en las cuales participan las memorias disidentes- como partes constitutivas de la historia y de las formas de apropiación del pasado. Muestra las disputas por las memorias que incluyen versiones letradas del poder político, y otras disidentes que gravitan entre visiones, emociones y acciones de sujetos rurales que habitan espacios sociales construidos como periféricos.

El quinto artículo, “'No olvidemos a los muertos'. Animero y violencia en Puerto Berrío, Antioquia (Colombia)” (Figueroa-Salamanca; Gómez-Sepúlveda, 2019), hace un interesante ejercicio de "descripción densa", como la sugiriera el antropólogo Clifford Geertz, de la adoración a las ánimas del purgatorio en este puerto del Magdalena Medio. Esta práctica religiosa popular se vio renovada por los cadáveres que llegaban a las playas de este epicentro del surgimiento y desarrollo de los grupos paramilitares en los años $8 \mathrm{o}$. El terrorismo y la violencia producida por los enfrentamientos de estos grupos con las guerrillas de las FARC y el ELN y la brutal violencia ejercida contra organizaciones sociales y líderes de derechos humanos, produjo centenares de muertos que fueron renombrados por los adoradores de las ánimas. Como lo expresan Figueroa-Salamanca y Gómez-Sepúlveda (2019: 129), nombrarlos era una forma de retornarles identidad y memoria, así como de "crear un hilo entre el allá (espacio sagrado) y el acá (el mundo de los vivos, el profano)”.

En el segundo grupo de artículos incluimos 4 que han llegado a la convocatoria permanente de la Revista CS, y que, desde perspectivas y propósitos diferentes, dialogan con los textos de memorias presentados antes. El primer artículo de este conjunto, "¿Qué es, cómo se hace y para qué sirve la teoría? Aportes desde la sociología y sus márgenes" (Fraga, 2019), resulta muy útil porque nos invita a preguntarnos sobre la contribución de los estudios de Colombia y América Latina a las teorías de memoria, y de paso ofrece guías de cómo recoger esos aportes para que ayuden en esa línea conceptual.

En particular, este texto muestra que las teorías requieren metáforas y analogías, así como historizaciones y anacronismos, como bien se puede observar en los aportes de los estudios de memoria incluidos en este número. También resultan útiles sus análisis sobre las ciencias sociales y la sociología que comparten la crítica a la concepción del plano ideal/conceptual/teórico como mero reflejo de los ámbitos materiales, históricos o empíricos. Por ello, propone concebir y estudiar la teoría como si tuviera una autonomía relativa, para así entender mejor cómo las teorías mismas entran a jugar un rol en la comprensión o explicación de estos planos, así como en su transformación, porque como lo afirma Fraga (2019: 195): “(...) los textos, (los) discursos o (los) enunciados no solo dicen cosas, sino que también hacen cosas". 
El segundo texto, "Intervención sistémica con familias: de la linealidad a la circularidad”, de Páez-Cala (2019), constituye una guía desde la ontología relacional y la complejidad de las interacciones múltiples entre agentes (humanos, naturales y tecnológicos), no solo para pensar los trabajos contemporáneos de investigación, sino también de acción social. Así, en primer lugar, propone trabajar en percepciones y comprensiones de los fenómenos sociales en términos de totalidades y no de partes aisladas e inconexas, así como una epistemología de los sistemas vivientes, en la que se reintroduce al observador sin pretensión de neutralidad y objetividad. Una investigación que conlleva a la observación del observador, es decir, a un observador observando su propia observación. En segundo lugar, se asume la intervención como un encuentro basado en una co-construcción, tanto en los procesos de orientación, educativos y de empoderamiento, como investigativos e incluso terapéuticos.

El tercer artículo de este bloque, "Propuesta de diseño de alojamientos rurales indígenas en la comunidad Nasa-Páez en Toribío, Cauca. Turismo y cultura en el posacuerdo" (Bolaños-Silva; Farfán-Sopó; Ruiz-Solano; González-Vallejo; Ruiz-Triana, 2019), pone en evidencia los impactos del conflicto armado en el Pacífico, particularmente en el Norte del Cauca, y muestra al turismo como una de las alternativas de subsistencia de las comunidades étnicas a partir de los patrimonios naturales y culturales de sus territorios. En este caso, el texto muestra el proceso de construcción de un proyecto común de arquitectura vernácula, con una propuesta de producción social del hábitat, con diferentes espacios de investigación y comunicación de los saberes y conocimientos, bajo el respeto de la ley de origen y la espiritualidad Nasa. El turismo se presenta aquí como una opción de sobrevivencia que se funda en las memorias e historias de los pueblos indígenas y negros, así como en sus patrimonios étnicos y naturales representados en sus territorios, cosmovisiones y ecosistemas naturales y productivos.

El cuarto y último artículo de este grupo, "Cambio institucional en la atención de la enfermedad mental en el Hospital Psiquiátrico San Isidro (1957-1970)", de Castrillón-Valderrutén y Sánchez-Salcedo (2019), muestra cómo las historias clínicas, surgidas de testimonios, pruebas y evidencia, constituyen una importante fuente de información sobre el cambio institucional. En este sentido, ellas tienen un valor tanto metodológico como analítico, e incluso pueden funcionar para proponer prospectivas y utopías. De manera particular, este trabajo busca identificar cambios históricos en la gestión institucional relacionados con la atención de los enfermos mentales del entonces Hospital Psiquiátrico San Isidro de la ciudad de Cali. Según Castrillón-Valderrutén y Sánchez-Salcedo (2019: 257), las historias clínicas "no solo evidencian una 'praxis clínica' y unos paradigmas médico-psiquiátricos pre- 
dominantes, sino que permiten otro tipo de análisis de historia social, al facilitar información demográfica, epidemiológica y del funcionamiento institucional de los establecimientos destinados a esta población".

En su muy interesante libro Ante el dolor de los demás, Susan Sontag (2003) evidencia cómo las imágenes y fotografías de las guerras, violencias y conflictos armados en diferentes tiempos y latitudes, tienen un inmenso poder ambivalente. Por una parte, tienen una gran capacidad para mostrar y visibilizar el dolor, la tragedia e indignidad de varias acciones humanas, y desde allí generar empatía con las víctimas y rechazo a los agresores y responsables. Pero, por otra parte, también pueden ayudar a la invisibilidad de las víctimas y a la naturalización de la violencia, así como a la estigmatización de personas, grupos o naciones. Esta ambigüedad, tal como se mostraba al inicio de este prólogo con el boom de las memorias, habla de la ineludible necesidad de atender la complejidad y multiplicidad de memorias e historias, y de trabajar por balances que aseguren la vida humana, natural, material y cultural. Balances entre asuntos delicados y sensibles como las verdades y los olvidos; las verdades y las justicias; las verdades y las responsabilidades; las verdades y las Historias (con h mayúscula). Balances, equilibrios y armonías que, en definitiva, apelan a necesarios consensos políticos, éticos y culturales que hagan posible la vida juntos.

El grupo de memorias, historias y análisis reunidos en este número, brindan desde lo local, lo particular y lo comunitario insumos muy valiosos para reconocer no sólo lo terrible y doloroso de muchas de las vivencias e historias de comunidades y personas en relación con la guerra y las violencias en diferentes territorios del país; también muestran la fuerza de personas, comunidades, organizaciones e instituciones que, en medio de la barbarie, la desesperanza y los atropellos a los derechos humanos y la dignidad humana, han logrado no sólo navegar y sobrevivir en medio de esas guerras y violencias, sino reinventar, rehacer y recrear sus vidas, sus rituales, su culturas, sus economías y acción política y democrática. Con lo anterior han dado muestras, han ofrecido ejemplos y referentes de gran generosidad, fortaleza y sabiduría, pero también de poder local, colectivo e institucional. Ahí dejamos este precioso grupo de experiencias y estudios para que ustedes se entusiasmen con ellos y puedan tejer sus propios mapas y cajas de herramientas, de manera que sirvan para los desafíos del mundo contemporáneo que estamos viviendo. Desafíos como los de la polarización política y social, que no solo han servido al desconocimiento de otros seres humanos, culturas y trayectorias, sino también del planeta mismo y de todos los seres que lo hemos habitado, incluidos patrimonios, historias y tradiciones territoriales, comunitarias y étnicas. 


\section{Referencias}

Huyssen, Andreas (2002). En busca del futuro perdido. Cultura y memoria en tiempos de globalización. México: FCE.

Nora, Pierre (2008). Pierre Nora en Les lieux de mémoire. Montevideo: Trilce.

Sontag, Susan (2003). Ante el dolor de los demás. Madrid: Alfaguara.

\section{Luis Fernando Barón}

Editor invitado

Universidad Icesi

Cali, junio de 2019 